\title{
Vegetative morphophysiological responses of four rice cultivars to drought stress
}

\author{
MIFTAHUDIN”, RURY ERYNA PUTRI, TATIK CHIKMAWATI \\ Department of Biology, Faculty of Mathematics and Natural Sciences, Institut Pertanian Bogor. J1 Agatis, Kampus IPB Darmaga, Bogor 16680, West \\ Java, Indonesia. Tel./fax.: +62-251-8622833, `email: miftahudin@apps.ipb.ac.id \\ Manuscript received: 28 June 2020. Revision accepted: 24 July 2020.
}

\begin{abstract}
Miftahudin, Putri RE, Chikmawati T. 2020. Vegetative morphophysiological responses of four rice cultivars to drought stress. Biodiversitas 21: 3727-3734. Each rice genotype develops certain morphophysiological responses to drought stress. The study aimed to analyze the morphophysiological responses of vegetative aspect of four rice cultivars to drought stress. A 10\% Polyethylene glycol-6000 was added to a Yoshida nutrient solution medium as a drought stress stimulant for four rice cultivars, i.e., IR64, Hawara Bunar, Situbagendit, and Inpago 10. Fourteen-days-old rice seedlings were grown on the media with and without drought stress treatment for 9 days, and morphophysiological characters of vegetative aspects were observed. Drought stress inhibited the shoot growth of cv. Hawara Bunar, but increased shoot growth of cv. Inpago 10. The physiological responses in the form of leaf relative water content, proline, malondialdehyde (MDA), and total chlorophyll contents in cv. Hawara Bunar was inversely proportional to those of cv. IR64 showed an inferior response to drought stress. The rice cv. Hawara Bunar might develop better response mechanisms to drought than that of cv. IR64. The physiological responses of cvs. Situbagendit and Inpago 10 were in between the other two cultivars. We conclude that the variation of morphophysiological responses to drought stress among rice cultivars is an indicator of tolerance capability to drought that could be used as early-growth selection criteria in rice breeding programs for drought tolerance.
\end{abstract}

Keywords: Drought, malondialdehyde, PEG-6000, proline, relative water content

\section{INTRODUCTION}

The world rice (Oryza sativa $\mathrm{L}$ ) consumption tends to increase $1.1 \%$ every year. However, the increase in rice productivity is only $1 \%$ per year (Shahbandeh 2020). The low productivity of rice can be caused by biotic and abiotic stresses. Biotic stress is a stress that causes damage on plant organs by other living organisms, for example, viruses, bacteria, fungi, parasites, insects, and weeds, while abiotic stress is any physical environment condition that prevents plants from achieving its full genetic potentials, such as metal toxicity, high temperature, flooding, salinity, and drought. Among those stresses, drought is considered as the most important cause of stress. Drought stress has twice the impact on the decrease of productivity of rice and other food crops compared to the impact of biotic stresses (Boyer 1982).

Drought stress is characterized by decreased water content, reduced water potential and loss of leaf cell turgor, and stomatal closure. Drought stress can interfere with nutrient absorption in plants, photosynthesis, and cellular metabolic processes. As the result, drought stress can cause a reduction in cell formation and growth which can ultimately inhibit the growth of shoot, roots, and plant biomass production, and if unabated it can cause death in plants (Farooq et al. 2009).

Plants respond, adapt, and survive to drought stress through the regulation of various morphological, biochemical, and physiological responses. Tolerant plants develop self-defense mechanisms against water shortages during drought (Farooq et al. 2009), which need to be examined in more detail. Several studies have shown that the accumulation of low molecular weight metabolites, such as proline, increases drought tolerance in plants through regulating cell osmotic potential during drought stress. Osmoregulators or solutes, one of which is proline, can stabilize structural proteins and cell plasma membranes. Osmoregulators are also able to assist plant adaptation to various adverse environmental conditions by decreasing the osmotic potential of the cytoplasm (Filippou et al. 2014).

Drought stress could induce reactive oxygen species (ROS) such as superoxide or hydrogen peroxide that can damage cell membrane phospholipid, which called lipid peroxidation. Malondialdehyde (MDA) content in the cell is an index measure to evaluate the level of cell membrane damage due to lipid peroxidation. The MDA is a highly reactive compound produced from lipid peroxidation and widely used as a marker of free radical production during or after stress (Fu and Huang 2001). The more MDA produced the more sensitive the plant to the stress, conversely low MDA content in the cell indicates that the cell is more tolerant of the stress. Therefore, the MDA content has been widely used as an indicator of tolerance level of the plant to the stress, including drought stress.

Cellular organelle damage that is triggered by the ROS formation can also be indicated with the total chlorophyll content of the leaves. The amount of leaf chlorophyll, i.e., chlorophyll a, chlorophyll b, and total chlorophyll, decreased under the drought stress (Ommen et al. 1999). The decreasing amount of leaf chlorophyll could occur as a consequence of 
chloroplast damage due to the formation of hydrogen peroxide in the stroma (Miller et al. 2010). Therefore, chlorophyll content in the leaf can also be used as an indicator of the tolerance level of the plant to drought stress.

In general, plants develop three defense mechanisms against drought stress, namely avoidance, escape, and tolerate stress (Bodner et al. 2015). The mechanism of plants in dealing with drought stress varies depending on the species or genotype of plants so that each species or genotype of plants can have different mechanisms and levels of tolerance. Rice plant has various cultivars, with varying degrees of tolerance to drought stress.

Rice is mostly cultivated as lowland rice, including rice cultivation in Indonesia. The lowland cultivation is very dependent on irrigation and sensitive to drought stress. During dry season, which is mostly occurs in the planting season from May to August, where water supply is very limited, drought stress could inhibit growth and decrease rice productivity or even fail to produce yield. The utilization of drought-tolerant rice cultivars could be one of the solutions to overcome the negative effects of drought stress. To date, there are many rice cultivars in Indonesia that have been considered as tolerant to drought, including Hawara Bunar, Situbagendit, and Inpago 10.

Development of rice cultivars with specific characters, such as tolerant to drought, requires long process, including a selection of parental lines, crossing the selected parents, selection of the pedigree, field trial for the selected lines, and finally releasing the lines as a variety. Each step of the breeding program will involve the use of a selection tool to characterize and select the parents and pedigrees for the desired trait, in this case, is drought tolerance characters. Vegetative morphological and physiological characters of rice in the early stage of the development are very useful characters to be used as a selection tool in breeding programs. When the characters are established, it will be very efficient to perform selection to a number of seedlings grown on simulated drought stress media for short time. However, the representative characters for drought tolerance need to be established first.

Study on the vegetative morphophysiological responses of several rice genotypes to drought stress in Indonesia is useful to obtain an initial knowledge to find rice genotypes that are tolerant to drought stress. The objective of this study was to analyze the morphophysiological responses of four rice cultivars, i.e., IR64, Hawara Bunar, Situbagendit, and Inpago10, to drought stress. In doing this, we investigated the response of rice growth and physiological characters at vegetative stage to the application of Polyethylene glycol (PEG-6000). The PEG-6000 is a polymer with a long, almost impermeable, non-ionic chain that can create good low water potential of the plant media (Sinhababu and Kar 2003). The use of PEG-6000 to induce drought stress in plants has been reported in peanut (Arachis hypogaea) (Meher et al. 2018) and barley (Hordeum vulgare L.) (Hellal et al. 2018). By applying $10 \%$ PEG-6000 in the solution media, low water potential of the solution media is created and causes drought stress to plant. The 10\% PEG-6000 reduces root and leaf relative water content and chlorophyll content in peanut (Meher et al. 2018) and significantly decreases shoot and root length, shoot and root dry weight, tissue water content, and seedling vigor in barley (Hellal et al. 2018). We expect the PEG-6000 can also be used to induce drought stress in several rice cultivars. The variation responses among cultivars to drought stress could be used as a tolerance parameter to evaluate rice cultivars in breeding programs for drought tolerance trait.

\section{MATERIALS AND METHODS}

\section{Plant materials}

Seeds of four rice cultivars, i.e. IR64, Hawara Bunar, Situbagendit, and Inpago 10, which we obtained from a rice germplasm collection of Muara Field Station of Bogor, Indonesian Center for Rice Research (BB PADI), Indonesian Agency for Agricultural Research and Development (IAARD), Indonesian Ministry of Agriculture, were used in the experiment. Rice cv. IR64 represented sensitive cultivar to drought, Hawara Bunar represented tolerant cultivar to drought, while Situbagendit and Inpago 10 were moderately tolerant to drought.

\section{Experimental design}

The experiment was arranged as a Completely Randomized Design (CRD) with two factors/treatments. The first treatment was rice cultivars, consisted of four rice cultivars, i.e. IR64, Hawara Bunar, Situbagendit, and Inpago 10. The second treatment was the drought stress treatment, i.e., without stress (control) and with drought stress. The drought stress was administered as an addition of $10 \%$ (w/v) PEG-6000 to the Yoshida nutrient culture medium (Yoshida et al. 1976). Each treatment was replicated three times with 10 plants for each replication.

\section{Drought stress treatment}

As many as 80 seeds for each cultivar were surfacesterilized using $1 \% \mathrm{NaOCl}$ for 15 minutes, rinsed with distilled water, and then soaked in distilled water for 24 hours at room temperature. Germination was carried out for two days in a dark room at room temperature. Two-day-old seedlings were then grown on Styrofoam floating on the Yoshida nutrient culture media (Yoshida et al. 1976). Ten uniform rice seedlings of each rice cultivar aged 12 days after planting (DAP) were transferred into a container contained 10\% PEG-6000 in $400 \mathrm{~mL}$ nutrient culture solution to stress the plants for 9 days (drought treatment). At the same time, another set of ten uniform rice seedlings of each rice cultivar were transferred to another container containing fresh nutrient solution without the addition of the PEG-6000 (control treatment). A set of drought and control treatments were replicated three times. Nutrient solutions were replaced after 5 days to keep constant $\mathrm{pH}$ 5.8 and nutrient content. The experiment was conducted in a growth chamber with 12 hours photoperiod at $28-29^{\circ} \mathrm{C}$.

\section{Observation of plant growth characters}

Plant growth characters, i.e., shoot height, primary root length, and dry weight of plant biomass were observed on 9 
days after treatment (DAT). Shoot height was measured using a ruler from the stem base up to the tip of the longest leaf. The roots of each plant were scanned, and the primary root length was measured using the ImageJ application (Sheffield 2007). The dry weight of plant biomass was measured by drying the shoot and roots of each plant at $80^{\circ} \mathrm{C}$ for 72 hours and weighed after having stable dry weight.

\section{Analysis of leaf relative water content}

Relative water content (RWC) of the leaves was observed at 9 DAT. Four fresh leaves of each treatment were weighed to obtain fresh weight. The leaves were then placed on the surface of distilled water and incubated for 24 hours at $4^{\circ} \mathrm{C}$. The leaves were then removed and quickly weighed to obtain turgid weight. The leaves were then dried at $80^{\circ} \mathrm{C}$ for 72 hours and weighed as dry weight. The leaf relative water content was calculated using the Barrs equation (Barrs 1968):

RWC (relative water content) : $\frac{\text { fresh weight }- \text { dry weight }}{\text { turgid weight }- \text { dry weight }}$ X 100

\section{Analysis of leaf proline content}

The leaf proline content was measured at 9 DAT based on the method developed by Bates et al. (1973). As much as $0.25 \mathrm{~g}$ rice leaves were ground in a mortar, homogenized in $5 \mathrm{~mL}$ of $5 \%$ sulfosalicylic acid solution, and then centrifuged at 10,000 rpm for 10 minutes. A two mL of leaf supernatant was reacted with $2 \mathrm{~mL}$ ninhydrin acid and 2 $\mathrm{mL}$ glacial acetic acid in a $15 \mathrm{~mL}$ falcon tube for 1 hour at $80^{\circ} \mathrm{C}$, then immediately incubated in ice water to decrease the temperature. The filtrate was extracted with $4 \mathrm{~mL}$ toluene, and then shaken vigorously using a vortex. Absorbance was measured by a spectrophotometer at $\lambda 520$ $\mathrm{nm}$. The proline concentration ( $\mu \mathrm{mol} \mathrm{\textrm {g } ^ { - 1 }}$ fresh weight) was calculated using the proline standard curve.

\section{Analysis of lipid peroxidation}

The level of lipid peroxidation was estimated by determining the malondialdehyde (MDA) concentration of the leaves and roots at 9 DAT. A $0.25 \mathrm{~g}$ leaves or roots were ground in a mortar and homogenized with $5 \mathrm{~mL}$ of $0.1 \%$ trichloroacetic acid (TCA). Homogeneous samples were centrifuged at 10,000 rpm for 10 minutes. Then, $1 \mathrm{~mL}$ of the supernatant was reacted with $4 \mathrm{~mL}$ of $0.1 \%$ thiobarbituric acid (TBA) in 20\% TCA, and then heated at $80^{\circ} \mathrm{C}$ for 30 minutes. Specific and non-specific absorbances were measured using spectrophotometers at $\lambda 532$ and 600 $\mathrm{nm}$, respectively. The MDA content was determined based on Mihara et al. (1980):

$$
[\mathrm{MDA}]=\frac{\left\{\left(\frac{\mathrm{A532}-\mathrm{A600}}{\varepsilon}\right)\right\} \times 10^{6}}{\text { wet weight }(\mathrm{g})}
$$

Where:

[MDA $]=$ MDA Concentration formed $\left(\mathrm{nmol} \mathrm{g}^{-1}\right)$ $\varepsilon=$ Extinction coefficient of MDA $\left(155 \mathrm{Mm}^{-1} \mathrm{~cm}^{-1}\right)$

\section{Analysis of chlorophyll content}

The measurement of chlorophyll content was carried out at 9 DAT using a method developed by Quinet et al. (2012) with a slight modification. As much as $0.1 \mathrm{~g}$ of fresh rice leaves were ground in a mortar, homogenized with $5 \mathrm{~mL}$ of $100 \%$ acetone, and then centrifuged at 2500 rpm for 10 minutes at $4^{\circ} \mathrm{C}$. Absorbance was measured with a spectrophotometer at $\lambda 470,645$, and $662 \mathrm{~nm}$. The leaf chlorophyll content was calculated using the following Lichtenthaler equation (Lichtenthaler 1987).

$$
\mathrm{C}_{a+b}=7.05 \mathrm{~A}_{662}+18.09 \mathrm{~A}_{645}
$$

Where:

$\mathrm{C}_{a+b}=$ total chlorophyll

$\mathrm{A}_{645}=$ absorbance at $\lambda 645 \mathrm{~nm}$

$\mathrm{A}_{662}=$ absorbance at $\lambda 662 \mathrm{~nm}$

\section{Data analysis}

The data obtained in the experiment were analyzed using a two-way analysis of variance (Two Way ANOVA) at a $95 \%$ confidence level using SPSS software version 16.0. Post hoc tests among treatments and their interactions were carried out using Duncan Multiple Range Test (DMRT) at $\alpha=0.05$.

\section{RESULTS AND DISCUSSION}

\section{Shoot and primary root growth}

Statistical analysis showed that there was interaction effect between rice cultivars and drought stress treatment in affecting shoot and primary root growth. Drought stress significantly inhibited shoot growth in cv. Hawara Bunar, but it promoted shoot growth in cv. Inpago 10. The shoot height of cv. IR64 and Situbagendit did not show any significant shoot height difference between drought stress and unstress treatments (Figure 1.A). Drought stress also inhibited the growth of the primary roots of three rice cultivars, i.e., IR64, Hawara Bunar, and Inpago 10, but increased the growth of the primary root of $\mathrm{cv}$. Situbagendit (Figure 1.B).

\section{Dry weight of plant biomass}

Drought stress caused a decrease in the dry weight of shoot and root biomass. Besides, drought stress also slightly decreased the shoot/root ratio (Table 1). Conversely, there is no significant difference in biomass dry weights among rice cultivars.

Table 1. Dry weight of rice plant biomass at 9 days after treatment under control and drought stress treatments

\begin{tabular}{lccc}
\hline \multirow{2}{*}{ Treatments } & \multicolumn{2}{c}{ Dry weight biomass (g) } & $\begin{array}{c}\text { Shoot: } \\
\text { Root Ratio }\end{array}$ \\
\cline { 2 - 3 } & Root & Shoot & $4.18 \mathrm{a}$ \\
Control & $0.049 \mathrm{~b}$ & $0.205 \mathrm{~b}$ & $4.05 \mathrm{a}$ \\
\hline Drought stress & $0.038 \mathrm{a}$ & $0.154 \mathrm{a}$ & 4.05 \\
\hline
\end{tabular}

Note: Numbers followed by the same letter in the same column are not significantly different in the DMRT test 


\section{Leaf relative water content}

The leaf relative water content of all rice cultivars under normal condition was relatively similar. However, a decrease in the leaf relative water content was found in all rice cultivars under the drought stress condition at 9 DAT (Figure 2). Rice cv. IR64 showed the highest decrease $(38.6 \%)$ in the leaf relative water content compared with the other rice cultivars (19.2-30.6\%). The leaf relative water content of cv. Hawara Bunar decreased 19.2\% from the condition without drought stress.

\section{Leaf proline content}

The observations showed that there were significant increases in leaf proline content of all rice cultivars that received drought stress treatment. The leaf proline content of all rice cultivars under the control condition showed that the proline content tends to be similar. The tremendous increase of leaf proline content occurred in rice cvs. IR64 and Situbagendit when stressed with drought, which was about 9 to 10 times higher than that of control, respectively, while the leaf proline content of rice cvs. Hawara Bunar and Inpago 10 only increase approximately 4 times (Figure 3 ).

\section{Lipid peroxidation in root and leaf cell membranes}

Quantitative analysis of lipid peroxidation of root cell membranes in the form of root MDA content showed a significant increase in three rice cultivars, i.e., cvs. IR64, Situbagendit, and Inpago10, in response to drought stress (Figure 4.A). The root MDA of rice cv. IR64 increased the highest (4.7 fold) compared to other cultivars, whereas the root MDA of rice cv. Hawara Bunar showed the least increase when both cultivars received drought stress treatment. The increase of the root MDA of the other two cultivars was in between cvs. IR64 and Hawara Bunar. Drought stress did not significantly affect the formation of MDA in the leaves of rice cvs. Hawara Bunar and Inpago 10 , but it significantly increased the leaf MDA in rice cvs. IR64 and Situbagendit (Figure 4.B). The lowest leaf MDA formation was found in rice cv. Inpago 10, while the highest was found in rice cv. IR64.

\section{Total leaf chlorophyll content}

The total leaf chlorophyll content in all rice cultivars decreased when treated with drought stress. There are significant decreases in the leaf chlorophyll content of rice cvs. IR64, Situbagendit, and Inpago 10 under drought conditions, whereas the reduction of the total leaf chlorophyll content in rice cv. Hawara Bunar is not significant (Figure 5). The greatest decrease in total leaf chlorophyll content is observed in rice cv. IR64 when it was treated with drought stress.

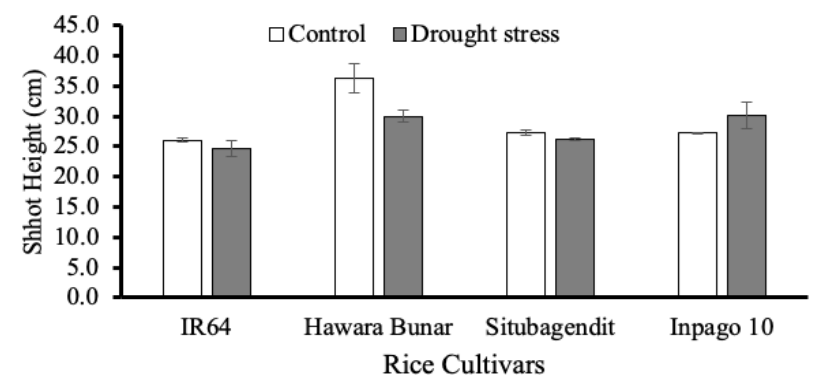

A

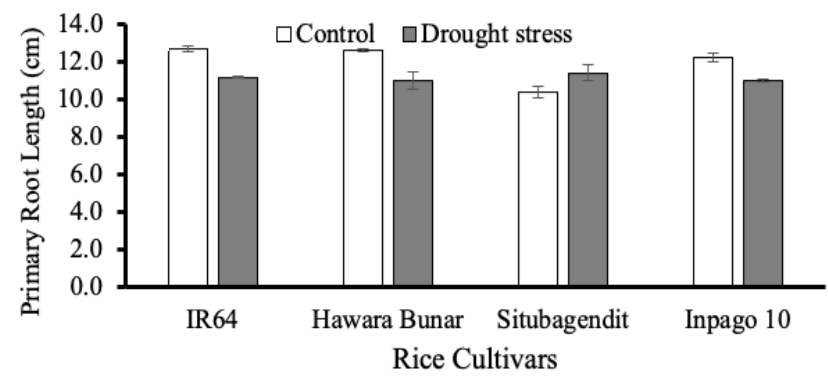

B

Figure 1. Shoot height (A) and primary root (B) of four rice cultivars at 9 days after drought and control treatments. The bar is the standard error of the mean

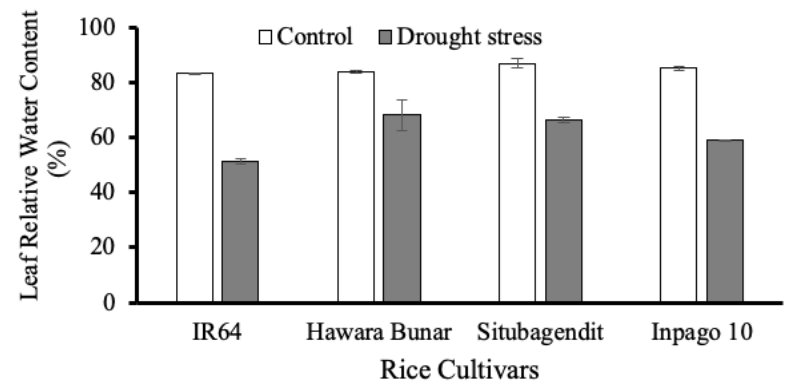

Figure 2. Leaf relative water content of four rice cultivars at 9 days after drought and control treatments. The bar is the standard error of the mean

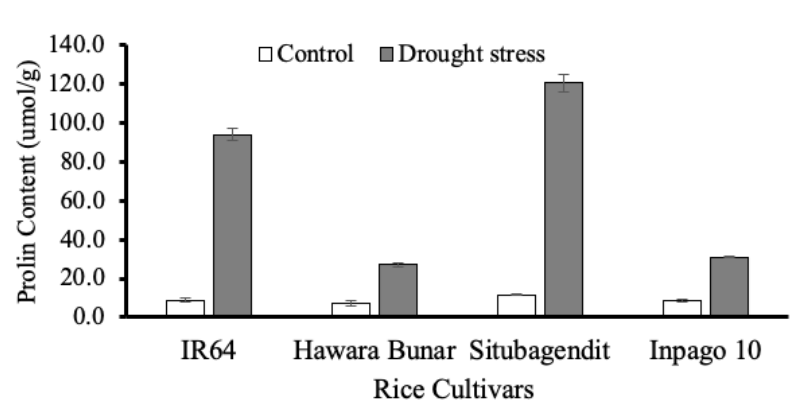

Figure 3. Leaf proline content of four rice cultivars at 9 days after drought and control treatments. The bar is the standard error of the mean 


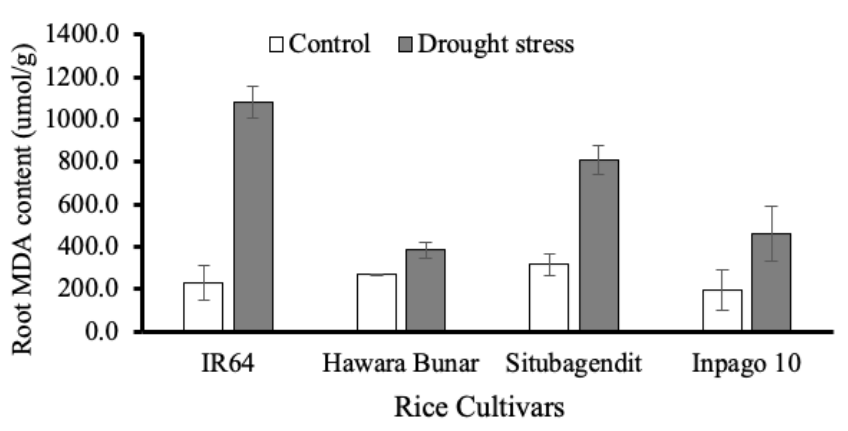

A

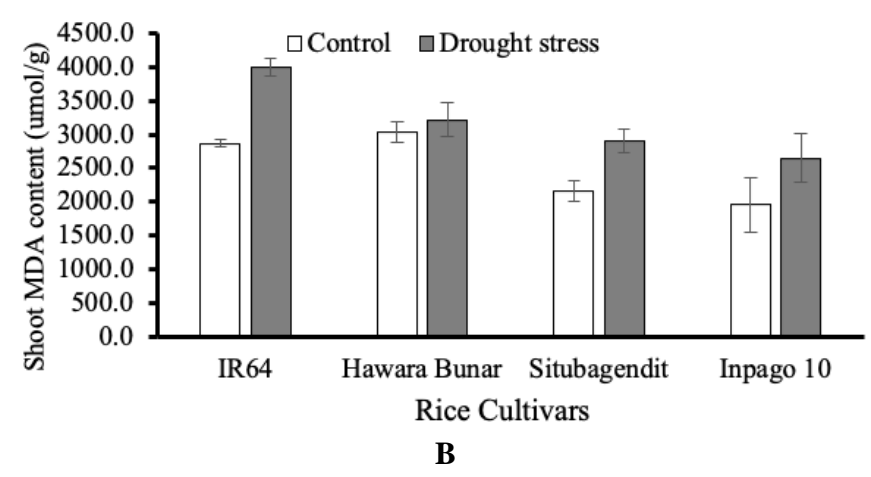

B

Figure 4. The root (A) and leaf (B) malondialdehyde (MDA) content of four rice cultivars at 9 days after drought and control treatments. The bar is the standard error of the mean

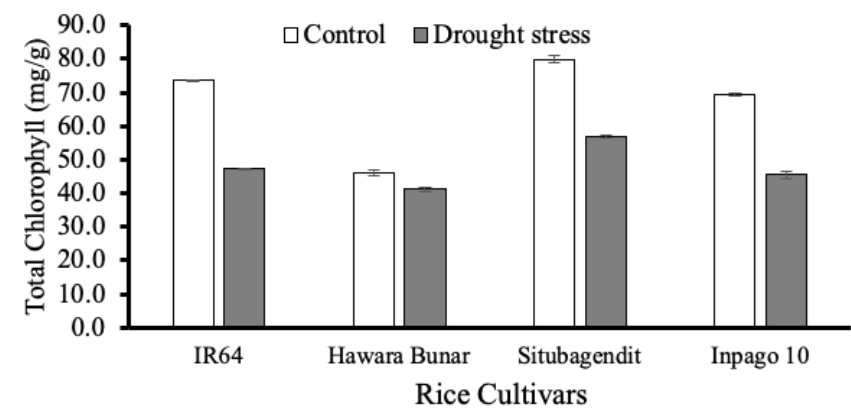

Figure 5. Total leaf chlorophyll content of four rice cultivars at 9 days after drought and control treatments. The bar is the standard error of the mean

\section{Discussion}

Plant's response to drought stress involves morphophysiological and molecular changes of the cells, tissue, and whole plant. The accumulation of permanent changes determines the ability of plants to maintain growth under a limited water supply. As a consequence, plant creates morphophysiological and molecular mechanisms that work in conditions that are adversely affected by drought. The mechanisms include stress avoidance, escape, and tolerance (Bodner et al. 2015). In general, the stress avoidance mechanism can be the optimization of water withdrawals and/or water storage strategies that make efficient use of water. One of the important parameters in the avoidance strategy is the ability of plant roots to grow deeper in the soils. Another response mechanism to drought stress is a tolerance mechanism, which is the survival mechanism through regulation of the cell osmotic potential, accumulation of osmoregulator compounds, and increase synthesis and activity of drought tolerance enzymes.

Drought stress lowers turgor pressure in the cells thereby inhibiting cell expansion and growth. Consequently, drought stress could regulate the shoot and root growth. In the current study, drought stress suppressed shoot growth in cv. Hawara Bunar, increased shoot growth in cv. Inpago 10 and did not significantly affect shoot growth of cvs. IR64 and Situbagendit (Figure 1.A). A lower rate in shoot growth by drought stress is related to a decrease in cell elongation. Another study also reported that drought stress inhibits leaf lengthening (Sacks et al. 1997). Different growth responses among rice varieties suggest that each variety has different strategies to overcome the drought.

Maintaining the root system during the drought condition provides advantages for maintaining adequate water supply to plants. The results of the experiment showed cv. Situbagendit has a significant increase in average root length when treated with drought stress (Figure 1B). Root lengthening behavior in cv. Situbagendit is an effort to adapt to water shortages. It is possible that cv. Situbagendit develops a mechanism to avoid stress by extending its roots during drought stress. Root lengthening can be achieved by maintaining the growth of the root tip cells in a drought stress condition. Consequently, roots, especially primary roots, appear thinner than that in normal conditions. Thinner roots are caused by limiting the rate of expansion of cells in the central cylindrical region and the cortical apical region of the root (Sharp et al. 2004).

On the other hand, the three other cultivars, i.e., IR64, Hawara Bunar, and Inpago 10 showed an inhibiting response of root growth to the drought stress. The roots of those cultivars were shorter under the drought condition than that of under control condition (Figure 1B), suggesting that the three cultivars develop a general response to drought in the form of growth inhibition of primary root and possibly develop lateral roots to adapt to drought condition. The differences in root responses between Situbagendit and the other three cultivars indicate that the root response to drought is not only affected by drought, but also genetically controlled (Sharp et al. 2004). The evidence is supported by the statistical analysis that showed the effect of significant interaction between cultivars and drought stress treatment on the primary root length.

Another growth character to measure the response of rice plant to drought condition is the dry weight of plant biomass. Based on the statistical analysis, there was no significant difference in biomass dry weight among cultivars, however, the biomass dry weight was affected by drought stress (Table 1). Drought stress reduces the production of biomass. The reduction in biomass is related to photosynthesis, temporal biomass production, and dry 
matter partitioning in the plant (Kage et al. 2004). The results showed a significant decrease in shoot and root biomass in all rice cultivars under drought conditions.

Drought stress did not significantly affect shoot: root ratio in all rice cultivars, although there is a tendency to decrease shoot: root ratio (Table1). The data suggests that the allocation of photosynthate between both the shoot and root is almost the same. This is probably because the age of the rice plants used in this experiment is relatively young, which is 23 day-old or is still in the early vegetative phase. The source transition and photosynthate distribution are related to the process of photosynthate translocation from the developing part to the mature part. The shoot and roots of young rice plants that continuously develop enable them to become strong photosynthate sink, therefore the dry matter in the two parts is not significantly different. Besides, in facing the water shortage, the plasticity of biomass distribution in the plant is specifically caused by the ontogenic tendency of the plant development phase (McConnaughay and Coleman 1999). For example, under drought conditions, parts of sorghum plants that remain green, such as young leaf buds, have higher dry biomass than that of the older parts (Borrell et al. 2000).

Relation to the growth character, there was a decrease in dry weight of cv. Situbagendit which seems to be a contradiction with the length of the primary root. Low root biomass of cv. Situbagendit that has the longest primary root might be due to the shrinking/thinning root diameter of cv. Situbagendit or the root cultivar develops aerenchyma structures that need further proof. This suggestion is strengthened by the results obtained by Yang et al. (2012) that report the drought stress treatment on several rice genotypes can increase aerenchyma formation in the root.

Drought stress decreased leaf water potential. Low water potential in the rhizosphere causes a water potential gradient between the rhizosphere and plant roots, which makes plant roots difficult to take water from the rhizosphere. The PEG-6000, can create good low water potential of the plant media. This condition can stimulate aerenchyma formation in root tissue, as is thought to occur in the root cv. Situbagendit. Although drought induction by PEG-6000 creates stress conditions more quickly, giving stress treatment to roots for 48 hours is sufficient to induce variation in leaf relative water potential among different rice genotypes as an indication of drought stress response at physiological and biochemical levels (Basu et al. 2010).

One of the physiological aspects of the plant that is affected by drought stress is the leaf relative water content, which reflects the balance between water supply to the leaves and transpiration rate (Schonfeld et al. 1988). In response to the low relative water content of the leaf tissue, plants will close stomata to reduce transpiration, which consequently will also reduce the rate of photosynthesis (Flexas and Medrano 2002). The result of relative water content analysis showed that there was a significant difference in leaf relative water content between untreated and treated plants with drought stress (Figure 2). Thus, the decrease in the leaf relative water content in droughtstressed plants occurs due to the decrease in water absorption from the rhizosphere. The lower rate of water absorption is also closely related to rice genotypes as evidenced by the decrease in the leaf relative water content, which is different among cultivars. Rice cv. IR64, which at the beginning of the treatment showing higher leaf relative water content than that of cv. Hawara Bunar, experienced a significant decrease in the leaf relative water content under drought stress compared to controls, from about 80 to $52 \%$. Rice cv. Hawara Bunar had low leaf relative water content since the beginning of treatment, then stabilized its value to 9 DAT, suggesting that cv Hawara Bunar has a response mechanism to drought through stabilization of leaf water potential.

A decrease in leaf water content can be caused by plants developing self-defense mechanisms in the form of osmoregulator accumulation. Proline is known as a compound that able to increase binding capacity of water and thereby could avoid organelle dehydration (Singh et al. 2015). Proline content analysis result showed that rice cv. IR64 responded to drought stress treatment by accumulating proline in its leaves. From this experiment, it appears that an increase in leaf proline content of cv. IR64 was much higher during the drought stress condition when compared to without drought stress treatment (Figure 3). Proline accumulation developed by cv. IR64 might be intended to keep the osmotic potential of the leaf cells low. Besides, the presence of proline accumulation is a signal to shape the plant's adaptive response to abiotic stress (Maggio et al. 2002). It can be interpreted that the high proline content in cv. IR64 leaves together with a significant decrease of leaf relative water content is a sign that cv. IR64 is more responsive to the drought condition compared to the other three cultivars. The other three cultivars, i.e., cvs. Hawara Bunar, Situbagendit, and Inpago10, only experienced a slight change in leaf proline content under drought stress conditions. The three cultivars may develop mechanisms other than the accumulation of proline in leaves or use other types of osmoregulator as an adaptive response to drought stress. From the leaf relative water content and leaf proline content data, it was found a positive correlation between stress treatment and a decrease in the relative water content and an increase in proline levels.

The accumulation of proline could protect and stabilize cell membranes and proteins, thereby avoiding them from damage caused by Reactive Oxygen Species (ROS) formed during stress conditions (Zhang et al. 2006). Besides, proline also reduces radical oxygen derivatives in the cells (Hoque et al. 2007). As mentioned earlier, the MDA content in the cell is a measure of the membrane damage due to ROS. The higher content of the MDA in the cell, the worse the cell membrane damage, or vice versa. In this study, rice cv. Hawara Bunar has the lowest increase in MDA content among the rice cultivars (Figure 4). The result implies that cv. Hawara Bunar has the least oxidative stress and cell membrane damage after drought stress. Different from cv. Hawara Bunar, cv. IR64 showed the highest increase in the MDA content both in the roots and leaves, indicating that the rice cv. IR64 experienced more severe damage to the cell membrane than that of $\mathrm{cv}$. Hawara Bunar. This suggests that the negative effect of 
ROS in cv. IR64 could not be alleviated by the high content of osmoregulator proline.

In addition to the root MDA, the leaves also produced MDA in a similar pattern with the root MDA as a response to drought. Rice cv. Hawara Bunar had the lowest increase of MDA content followed by cvs. Inpago 10 and Situbagendit, whereas cv. IR64 had the highest MDA increase (Figure 4A). The low leaf MDA content in cv. Inpago 10 indicates that $\mathrm{cv}$. Inpago 10 might form a defense mechanism against drought stress in the form of tolerance such as cv. Hawara Bunar. This is supported by MDA root of $\mathrm{cv}$. Inpago 10, which was quite low when compared to cv. Situbagendit and IR64 (Figure 4B). The low MDA content of the leaves indicates the level of cell membrane damage in leaf cells of cv. Inpago 10 is also quite low, which it might be due to the ability to $\mathrm{cv}$. Inpago 10 to withstand the membrane destruction by ROS with other mechanisms, such as the accumulation of osmoregulator or the formation of oxidative stress-tolerant enzymes. The osmoregulator accumulation in the leaves can maintain the osmotic potential associated with the stability of the leaf cell membrane as an important indicator in dealing with drought stress.

The results of the leaf chlorophyll content analysis showed that there was a decrease in the total chlorophyll content under the drought stress condition in all rice cultivars. The greatest decrease of the leaf chlorophyll content was found in cv. IR64 and Situbagendit (Figure 5). Rice cv. Hawara Bunar showed the lowest decrease in the leaf chlorophyll content compared to the other cultivars. The rice cv. Hawara Bunar seems to be more successful in dealing with chlorophyll damage due to ROS production during drought stress through other adaptive responses. The suggestion is supported by the low MDA content in cv. Hawara Bunar. Thus, cv. Hawara Bunar is the most tolerant and adaptive rice cultivar to the drought stress among the rice cultivars used in this experiment.

In conclusion, drought stress decreases the length of the primary roots in all rice cultivars, except for rice cv. Situbagendit. It is possible that cv. Situbagendit develops a mechanism to avoid drought stress through the root lengthening. The drought stress also decreases the dry weight of plant biomass in all rice cultivars. Physiological responses of rice plant to drought are indicated by the values of the leaf relative water content, proline content, MDA content, and total chlorophyll content. The leaf relative water content, MDA content, leaf proline, and total leaf chlorophyll contents of rice cv. Hawara Bunar was inversely proportional to those of cv. IR64. Rice cv. IR64 shows a large decrease in the leaf relative water content and total chlorophyll content, but it shows a larger increase in the leaf proline and MDA content compared to the other three cultivars. Rice cv. Hawara Bunar is the most tolerant to drought stress, followed by cvs. Inpago 10, Situbagendit, and IR64, respectively. Various morphophysiological responses of four rice cultivars to drought stress suggests that each rice cultivar adapts differently to drought stress.

\section{ACKNOWLEDGEMENTS}

The research was partially funded by the Ministry of Research, Technology, and Higher Education, the Republic of Indonesia, through International Collaboration and Scientific Publication grant F.Y. 2016 to $\mathrm{M}$ with contract number: 374/IT3.11/PN/2016. We thank Muara Field Station, Indonesian Center for Rice Research (BB PADI), IAARD, Ministry of Agriculture, the Republic of Indonesia for providing seed materials for this research.

\section{REFERENCES}

Barrs HD. 1968. Determination of water deficits in plant tissues. In: Kozolvski TT (ed.). Water Deficits and Plant Growth. Academic Press, New York.

Bates LS, Waldren RP, Teare ID. 1973. Rapid determination of free proline for water-stress studies. Plant Soil 39: 205-207.

Bodner G, Nakhforoosh A, Kaul HP. 2015. Management of crop water under drought: a review. Agron Sustain Dev 35: 401-442. DOI: 10.1007/s13593-015-0283-4.

Borrell AK, Hammer GL, Henzell RG. 2000. Does maintaining green leaf area in sorghum improve yield under drought? II. Dry matter production and yield. Crop Sci 40: 1037-1048. DOI: 10.2135/cropsci2000.4041037x.

Boyer JS. 1982. Plant productivity and environment. Science 218: $443-$ 448. DOI: 10.1126/science.218.4571.443.

Farooq M, Wahid A, Kobayashi N, Fujita D, Basra SMA. 2009. Plant drought stress: effects, mechanisms and management. Agron Sustain Dev 29: 185-212. DOI: 10.1051/agro:2008021.

Filippou P, Bouchagier P, Skotti E, Fotopoulos V. 2014. Proline and reactive oxygen/nitrogen species metabolism is involved in the tolerant response of the invasive plant species Ailanthus altissima to drought and salinity. Environ Exp Bot 97: 1-10. DOI: 10.1016/j.envexpbot.2013.09.010.

Flexas J, Medrano H. 2002. Drought-inhibition of photosynthesis in C3 plants: stomatal and non-stomatal limitations revisited. Ann Bot 89 (2): 183-189. DOI: $10.1093 / \mathrm{aob} / \mathrm{mcf027}$.

Fu J, Huang B. 2001. Involvement of antioxidants and lipid peroxidation in the adaptation of two cool-season grasses to localized drought stress. Environ Exp Bot 45 (2): 105-114. DOI: 10.1016/s00988472(00)00084-8.

Hellal FA, El-Shabrawi HM, Abd El-Hady M, Khatab IA, El-Sayed SAA, Abdelly C. 2018. Influence of PEG induced drought stress on molecular and biochemical constituents and seedling growth of Egyptian barley cultivars. J Genet Eng Biotechnol 16 (1): 203-212. DOI: 10.1016/j.jgeb.2017.10.009.

Hoque MA, Banu MNA, Okuma E, Amako K, Nakamura Y, Shimoishi Y, Murata Y. 2007. Exogenous proline and glycine betaine increase $\mathrm{NaCl}$-induced ascorbate-glutathione cycle enzyme activities, and proline improves salt tolerance more than glycine betaine in tobacco Bright Yellow-2 suspension-cultured cells. Plant Physiol 164 (11): 1457-1468. DOI: 10.1016/j.jplph.2006.10.004.

Kage HM, Kochler M, Stützel H. 2004. Root growth and dry matter partitioning of cauliflower under drought stress conditions: Measurement and simulation. European J Agron 20: 379-394. https://doi.org/ 10.1016/s1161-0301(03)00061-3.

Lichtenthaler HK. 1987. Chlorophylls and carotenoids: Pigments of photosynthetic biomembranes. Methods Enzymol 148: 350-382. DOI: 10.1016/0076-6879(87)48036-1.

Maggio A, Miyazaki S, Veronese P, Fujita T, Ibeas JI, Damsz B, Narasimhan ML, Hasegawa PM, Joly RJ, Bressan RA. 2002. Does proline accumulation play an active role in stress-induced growth $\begin{array}{lllll}\text { reduction?. Plant J } 31 & \text { (6):6 } & 99-712 & \text { DOI: } 10.1046 / j .1365-\end{array}$ 313X.2002.01389.x.

Meher, Shivakrishna P, Ashok Reddy K, Manohar Rao D. 2018. Effect of PEG-6000 imposed drought stress on RNA content, relative water content (RWC), and chlorophyll content in peanut leaves and roots. Saudi J Biol Sci 25 (2): 285-289. DOI: 10.1016/j.sjbs.2017.04.008. 
McConnaughay KDM, Coleman JS. 1999. Biomass allocation in plants: ontogeny or optimality? A test along three resource gradients. Ecology 80 (8): 2581-2593.

Mihara M, Uchiyama M, Fukuzawa K. 1980. Thiobarbituric acid value on fresh homogenate of rat as a parameter of lipid peroxidation in aging, $\mathrm{CCl} 4$ intoxication, and vitamin E deficiency. Biochem Med 23 (3): 302-311. DOI: 10.1016/0006-2944(80)90040-x.

Miller G, Suzuki N, Ciftci-Yilmaz S, Mittler R, 2010. Reactive oxygen species homeostasis and signalling during drought and salinity stresses. Plant Cell Environ 33 (4): 453-467.

Ommen JOE, Donnelly A, Vanhoutvin S, van Oijen M, Manderscheid R. 1999. Chlorophyll content of spring wheat flag leaves grown under elevated $\mathrm{CO} 2$ concentrations and other environmental stresses within the 'ESPACE-wheat" project. Europ J Agro 10 (3-4): 197-203. DOI 10.1016/S1161-0301(99)00011-8

Quinet M, Vromman D, Clippe A, Bertin P, Lequeux H, Dufey I, Lutts S, Lefevre I. 2012. Combined transcriptomic and physiological approaches reveal strong differences between short-and long-term response of rice (Oryza sativa) to iron toxicity. Plant Cell Environ 35 (10): 1837-1859.

Sacks MM, Silk WK, Burman P. 1997. Effect of water stress on cortical cell division rates within the apical meristem of primary roots of maize. Plant Physiol114 (2): 519-527.

Schonfeld MA, Johnson RC, Carver BF, Mornhinweg DW. 1988. Water relations in winter wheat as drought resistance indicators. Crop Sci 28 (3): 526-531.
Shahbandeh M. 2020. Total global rice consumption 2008-2020. https://www.statista.com/statistics/255977/total-global-riceconsumption/

Sharp RE, Poroyko V, Hejlek LG, Spollen WG, Springer GK, Bohnert HJ, Nguyen HT, 2004. Root growth maintenance during water deficits: physiology to functional genomics. J Exp Bot 55: 2343-2351. DOI: $10.1093 / \mathrm{jxb} / \mathrm{erh} 276$.

Sheffield JB. 2007. ImageJ, a useful tool for biological image processing and analysis. Micros Microanal 13 (S2): 200-201.

Singh M, Kumar J, Singh S, Singh VP, Prasad SM. 2015. Roles of osmoprotectants in improving salinity and drought tolerance in plants: a review. Rev Environ Sci Biotechnol 14 (3): 407-426.

Sinhababu A, Kar RK. 2003. Comparative responses of three fuelwood yielding plants to PEG-induced water stress at seedling stage. Act Physiol Plant 25 (4): 403-409.

Yang X, Li X, Ren B, Ding L, Gao C, Shen Q, Guo S. 2012. Droughtinduced root aerenchyma formation restricts water uptake in rice seedlings supplied with nitrate. Plant Cell Physiol 53 (3): 495-504.

Yoshida S, Forno DA, Cock JH, Gomez KA. 1976. Laboratory Manual for Physiological Studies of Rice. 3rd ed. International Rice Research Institute. Philippine.

Zhang X., Zhou S, Fu Y, Su Z, Wang X, Sun C, 2006. Identification of a drought-tolerant introgression line derived from Dongxiang common wild rice (O. rufipogon Griff.). Plant Mol Biol 62: 247-259. DOI: 10.1007/s11103-006-9018-x. 